BLS 33, No 1 2007. DOI: http://dx.doi.org/10.3765/bls.v33i1.3541

(published by the Berkeley Linguistics Society and the Linguistic Society of America)

\title{
The Japanese Contrastive Wa: A Mirror Image of EVEN*
}

\author{
OSAMU SAWADA \\ University of Chicago
}

\section{Introduction}

Many studies have been made of the Japanese contrastive wa (Kuno 1973a, b, Teramura 1991, Noda 1996, Nakanishi 2001, Hara 2006, Oshima to appear, among others). However, they have analyzed the semantics/pragmatics of contrastive wa without considering ( $\mathrm{i}$ ) the scalar value and (ii) the possibility that contrastive wa has multiple meanings (conventional implicatures).

The purpose of this paper is to argue that there are two types of contrastive $w a$ - scalar contrastive $w a$ and polarity contrastive $w a$ - and that the scalar type has conventional implicatures that are a 'mirror image' of those of sae/mo 'even'. (1) is an example of the scalar type and (2) is an example of the polarity type:

(Do you have a vehicle?)

Jitensya wa mot-tei-masu.

Bicycle Cont have-State-polite

'I have [a bicycle] $]_{\text {Cont. }}$ '

$\rightarrow$ I don't have more expensive vehicles than a bicycle (e.g. a motor cycle)

(2.) (Have all of the members (e.g. Taro, Hanako, Ziro) arrived at Chicago?)

Taro wa tuki masi-ta.

Taro Cont arrive polite-perfect

'[Taro] Cont has arrived.'

$\rightarrow$ There is someone other than Taro who has not arrived at Chicago.

This paper proposes the following points: (a) The conventional implictures/presuppositions (Karttunen and Peters 1979) of contrastive wa can be a 'mirror image' of those of sae/mo. This fact naturally explains why contrastive

\footnotetext{
* I would like to thank Anastasia Giannakidou, Chris Kennedy, Jerry Sadock, and Keiko Yoshimura for valuable discussion on this material. I would also like to thank Amy Dahlstrom, Michael Ellsworth, Michael Yoshitaka Erlewine, Paul Kay, Russel Lee-Goldman, Dmitry Levinson, Harumi Sawada, Jun Sawada, Suwon Yoon, and the audience of BLS 33 for their helpful comments.
} 


\section{Osamu Sawada}

$w a$, but not sae/mo, can induce a conventional quantity (scalar) implicature. (b) There is, however, a case in which contrastive wa seems not to induce a conventional Q implicature. In contrast to the case of sae, the scalar presupposition is 'optional' for contrastive $w a$, and this optionality induces a different type of implicature, a 'polarity reversed conventional implicature/ presupposition' (Lee 2006, Oshima to appear). The quantificational force of the implicature in polarity contrastive $w a$ can be pragmatically strengthened to become universal $(\forall)$ in some contexts, while in other cases it can be epistemically weakened to become existential $(\exists)$ with a possibility operator $\triangle \varnothing$. $\quad$ (c) The precise mirror image of contrastive $w a$ is expressed by $m o$, which is semantically ambiguous between 'even' and 'also.' (d) If we posit the existence of two types of contrastive wa, we can unify two seemingly incompatible approaches to this particle: the 'reversed polarity approach' (Kuno 1973a, b, Teramura 1991, Noda 1996, Oshima to appear) and the 'scalar alternative approach' (Hara 2006, to appear).

\section{Background: Thematic $W a$ vs. Contrastive $W a$}

It is well known that the particle $w a$ in Japanese has two kinds of uses, thematic and contrastive (Kuno 1973a, b, Teramura 1991, Noda 1996, Nakanishi 2001, Oshima to appear, among many others).

(3.) Taro $\boldsymbol{w a}$ hasi-ttei-ru.

Taro run -Prog-pres

a. Thematic wa: 'Speaking of Taro, he is running.'

b. Contrastive wa: 'Taro is running (but Hanako is not running.)'

(Kuno 1973a: 207)

In (3a), wa marks a constituent that stands for a theme, as opposed to a comment. According to Kuno (1973a, b), such themes must be either generic or anaphoric (i.e. previously mentioned). By contrast, in (3b), wa marks the contrasted element of the sentence, and conventionally implies that there is an element that is alternative to it. Notice that the element marked by contrastive wa can be generic, anaphoric or neither (Kuno 1973a, b). That is, the element does not always have to be topical. ${ }^{1}$ We should also notice that thematic $w a$ is phonologically different from contrastive $w a$ (Nakanishi 2001, Oshima to appear). If we put a stress on $w a$, it is interpreted as contrastive. This paper focuses solely on contrastive $w a$.

\section{Previous Analyses of Contrastive $W a$}

\footnotetext{
${ }^{1}$ Since contrastive $w a$ always posits an alternative element or elements other than the one it marks and induces an 'anti-additive' implicature, it is safe to consider it a kind of focus-sensitive operator (Oshima to appear). Notice, however, that the element marked by contrastive $w a$ can be either given or new information. This suggests that the concept of contrastiveness is independent from the distinction between given and new information.
} 


\section{The Japanese Contrastive Wa}

In languages like Japanese and Korean, contrast is marked morphologically, while in a language like English it is marked phonologically. Two theories have been proposed to explain the implicature of contrastive $w a$; these may be termed the reversed polarity approach and the scalar alternative approach. The reversed polarity approach says that the implicature induced by contrastive $w a$ has an meaning opposite to the stated one: ' $\mathrm{X}$ wa...' implies 'but it not the case that $\mathrm{y}$ wa...)' (Kuno 1973a, b, Teramura 1991, Noda 1996, Oshima to appear, among others). Some researchers call this the "polarity reversed conventional implicture/ presupposition' (Lee 2006, Oshima to appear).

The scalar alternative approach, on the other hand, says that contrastive wa always induces a conventional scalar implicature (Hara 2006, to appear). Hara (2006, to appear) claims that "a contrastive topic presupposes a particular set of scalar alternatives, namely stronger propositions than the asserted one and the implicature induced by the contrastive $w a$ is a conventional Q implicature." Notice that Hara (2006, to appear) does not say that the contrastive wa has a scalar value. I will argue that the 'scalar type' of contrastive $w a$ has a scalar value that is a mirror image of sae/mo 'even'.

Both approaches consider an implicature induced by contrastive wa conventional, but not conversational. Applying the detachability test, we find that the implicature in (4a) is detachable because (4b), which has the same semantic content as (4a), does not normally induce the implicature:

[Detachability test: detachable]

a. Hanako wa jitensya wa mot-tei-ru.

Hanako Top bicycle Cont have-state-pres

'Hanako has [a bicycle] cont.'

$\rightarrow$ Hanako doesn't have more expensive vehicles than a bicycle.

b. Hanako иa jitensya o mot-tei-ru.

Hanako Top bicycle ACC have-state-pres

'Hanako has a bicycle.' (The implicature is not obligatory)

According the cancellability test, the implicature is not cancelable:

[Cancelability test: non-cancelable]

\#Hanako wa jitensya wa mo-ttei-ru-si, ootobai mo

Hanako Top bicycle Cont have-state-pres-and motor cycle also/even

mot- tei-ru.

Have-state-pres

'Hanako has [a bicycle $]_{\text {cont }}$ and she $\{$ also/even $\}$ has a motor cycle.'

Both the reversed polarity approach and the scalar alternative approach consider the implicature induced by contrastive $w a$ conventional, but not conversational. However, their explanations of this fact are different. The reversed polarity 


\section{Osamu Sawada}

approach does not posit a scale, while the scalar alternative approach does. Can we unify these accounts?

I will argue that there are two kinds of contrastive $w a$, scalar contrastive wa and polarity contrastive $w a$. This theory makes it possible to unify the two seemingly different approaches.

\section{Scalar Contrastive Wa: A Mirror Image of EVEN}

\subsection{Positive Case}

Let us observe the following examples: (Context: Amateurs, semi-professionals, and professionals are participating in a tennis tournament.)

(6.) Taro wa sirooto ni $\{\boldsymbol{w a} /$ ??sae $\}$ ka- tta. Taro Top amateur Dat cont / even win-past '(lit.) Taro beat an [amateur] cont. /??Taro even beat an amateur.'
Taro wa puro ni
$\{?$ ?wa $/$ sae $\}$ Taro Top professional Dat cont / even win-past
ka -tta. '(lit.) ??Taro beat a [professional $]_{\text {cont }} /$ Taro beat even a professional.'

There is a clear difference in acceptability between contrastive $w a$ and sae in each of above sentences. The conventional implicatures of (6) with contrastive $w a$ are as follows:

(8.) Scalar contrastive $w a$ (positive):

a. $\exists \mathrm{x}[\mathrm{C}(\mathrm{x}) \wedge \mathrm{x} \neq$ amateur $\wedge \neg$ beat (Taro, $\mathrm{x})]$

b. $\forall \mathrm{x}[\mathrm{C}(\mathrm{x}) \wedge \mathrm{x} \neq$ amateur $\rightarrow$ unlikelihood (Taro beat $\mathrm{x})>$ unlikelihood (Taro beat an amateur)]

The combination of $(8 a)$ and $(8 b)$ produces the conventional quantity implicature that 'Taro could not beat a tennis player who is stronger than an amateur.' ${ }^{2}$ On the other hand, in (7) sae has a positive existential presupposition and forces us to construe the proposition as high on this scale, as shown in (9b):

(9.) Sae 'even' (positive):

a. $\exists \mathrm{x}[\mathrm{C}(\mathrm{x}) \wedge \mathrm{x} \neq$ professional $\wedge$ beat (Taro, $\mathrm{x})]$

b. $\forall \mathrm{x}[\mathrm{C}(\mathrm{x}) \wedge \mathrm{x} \neq$ professional $\rightarrow$ unlikelihood (Taro beat a professional) $>$ unlikelihood (Taro beat $\mathrm{x}$ )]

Note that (7) with sae does not induce a conventional quantity implicature.

\footnotetext{
${ }^{2}$ If 'semi-professional' is substituted here, the sentences with contrastive $w a$ and sae both become acceptable. This is because the element can be construed as 'low' relative to a professional but 'high' relative to an amateur (cf. Kay 1990).
} 


\section{The Japanese Contrastive $\mathrm{Wa}$}

\subsection{Negative Case}

Contrastive $w a$ and sae can also appear in a negative environment, where the scalar values are reversed:

(Context: Amateurs, semi-professionals and professionals are participating in a tennis tournament.)

(10.) Taro wa sirooto ni \{??wa / sae $\}$ kata-na-katta. (cf. (6)) Taro Top amateur Dat cont / even win-not past '(lit.) Taro didn't beat an [amateur $]_{\text {cont }}$ / Taro didn't even beat an amateur.'
Taro wa puro
ni $\{\boldsymbol{w a} /$ ??sae $\}$ kata-na-katta. (cf. (7))

Taro Top professional Dat cont / even win-not-past

'Taro didn't beat a [professional $]_{\text {cont. }} /$ ??Taro didn't even beat a professional.'

When contrastive $w a$ is used in a negative context, the proposition without a negative operator is construed as high on the scale of 'unlikelihood', whereas with sae, the proposition without a negative operator is construed as low on this scale. The conventional implicatures of (10) with sae and (11) with contrastive wa can be represented as (12) and (13), respectively: ${ }^{3}$

(12.) Scalar contrastive $w a$ (neg):

a. $\exists \mathrm{x}[\mathrm{C}(\mathrm{x}) \wedge \mathrm{x} \neq$ professional $\wedge$ beat (Taro, $\mathrm{x})]$

b. $\forall \mathrm{x}[\mathrm{C}(\mathrm{x}) \wedge \mathrm{x} \neq$ professional $\rightarrow$ unlikelihood (Taro beat professional) $>$ unlikelihood (Taro beat $\mathrm{x})$ ]

(13.) Sae (neg):

a. $\exists \mathrm{x}[\mathrm{C}(\mathrm{x}) \wedge \mathrm{x} \neq$ amateur $\wedge \neg$ beat (Taro, $\mathrm{x})]$

b. $\forall \mathrm{x}[\mathrm{C}(\mathrm{x}) \wedge \mathrm{x} \neq$ amateur $\rightarrow$ unlikelihood (Taro beat $\mathrm{x})>$ unlikelihood (Taro beat an amateur)]

\subsection{Scope Inversion}

In Japanese, there is a phenomenon of scope inversion using contrastive marking (Hara to appear, Oshima to appear, Lee 2000).

a. John wa zen-in o tasuke-nakat-ta. John op everyone Acc help Neg Past 'John didn't hdp anone.' $\quad(\forall>\neg)$ '?? It is not the case that John helped everyone.' $(\neg>\forall)$

\footnotetext{
${ }^{3}$ The conventional implicatures of the negative sentences with contrastive $w a$ and sae are represented based on the framework of polarity theory (Rooth 1985, Rullmann 1997, Giannakidou 2007, Yoshimura (to appear)). There is also a framework of scope theory (Karttunen and Peters 1979).
} 


\title{
Osamu Sawada
}

\author{
b. John wa zen-nin $\boldsymbol{w a}$ tasuke-nakat-ta. \\ John op everyone Cont help Neg Past \\ '*John didn't help anyone.' $\quad(\forall>\neg)$ \\ 'It is not the case that John helped everyone.' $(\neg>\forall)$
}

The reading of $(\forall>\neg)$ in (14b) is not acceptable because it does not satisfy the existential presupposition of contrastive $w a$. In the negative context, contrastive wa has to have a positive existential conventional implicature, as in (15):

(15.) Scalar contrastive $w a$ (neg): $(\mathrm{QP}=$ quantifier phrase)

a. $\exists \mathrm{QP}[\mathrm{C}(\mathrm{QP}) \wedge \mathrm{QP} \neq$ everyone $\wedge$ helped (John, QP)]

b. $\forall \mathrm{QP}[\mathrm{C}(\mathrm{QP}) \wedge \mathrm{QP} \neq$ everyone $\rightarrow$ unlikelihood (John helped everyone) $>$ unlikelihood (John helped QP)]

The reading of $(\neg>\forall)$ in (14b) is acceptable because the sentence has a positive existential presupposition.

\section{Additional Empirical Evidence for the Existence of Scalar Type}

Teramura (1991: 40) and Noda (1996: 224) point out that contrastive $w a$ is interpreted as sukunaku-tomo 'at least', if combined with numerals. Does this use of contrastive $w a$ only occur with numerals? The answer is no. I argue that scalar contrastive $w a$ is not an ad hoc usage. It 'inherently' has a scalar value that forces the addressee to interpret the proposition as low on the scale of unlikelihood in the positive case and high on this scale in the negative case.

\subsection{Comparative Yori plus Contrastive $W a$}

If contrastive $w a$ is attached to yori, the standard of comparison is construed as low on a given scale, as shown in (16b):

a. Tarowa Ziro yori se ga takai.

Taro Top Ziro than height Nom tall

'Taro is taller than Ziro.'

b. Taro wa Ziro yori-wa se ga takai.

Taro Top Ziro than-cont height Nom tall

'Compared to Ziro, Taro is tall.'

$\rightarrow$ Ziro is hort. (Implicature from the standard of comparison)

$\rightarrow$ Taro is not definitely tall. (Implicature from the main clause)

Notice that there is another implication as well: that 'Taro is not definitely tall' (Sawada 2007). 


\section{The Japanese Contrastive Wa}

\subsection{Predicate with Contrastive $\mathrm{Wa}$}

A scalar value also arises when contrastive $w a$ is attached to the predicate of a sentence (i.e. adjective, verb):

$$
\begin{aligned}
& \text { Ame wa furi wa ri-ta. } \\
& \text { Rain Top fall Cont do-past } \\
& \text { 'It [rained] }]_{\text {cont.' }} \\
& \rightarrow \text { (Implicature): It didn't rain a lot. (low amount) }
\end{aligned}
$$

\subsection{Polar Question (Negative Bias)}

Positive questions with minimizers can express a negative bias (Borkin 1971, Ladusaw 1979, Giannakidou 2007, among others):

(18.) Did Tom lift a finger to help?

(Bias: No, he didn't.)

Contrastive $w a$ can also be used in a positive question with a negative bias.

(19.) $\mathrm{X}$ daigaku ni wa ukari-masi-ta-ka. (X university is easy to enter.)

$\mathrm{X}$ university Dat Cont pss- polite-past-Q

'Were you accepted by $[\mathrm{X} \text { university }]_{\text {cont? }}$ ?

(Bias: No you weren't.)

This fact supports the idea that scalar contrastive $w a$ has a low scalar value.

\section{The Mirror Image in Rullmann's Typology of Even-Items}

Rullmann (2006) proposes a four-way typology of even-items, which is analogous to Israel's (1996) typology of polarity items. Israel (1996) proposes two kinds of parameters for the typology of polarity items:

(20.) Quantitative Value (Q): high or low relative to norm Informative Value (I): understating or emphatic relative to norm

Based on these parameters, Rullmann (2006) proposes the following typology of even-items:

(21.) Rullmann's four-way typology of even

\begin{tabular}{|l|l|c|c|c|}
\cline { 3 - 5 } \multicolumn{2}{c|}{} & \multicolumn{2}{c|}{ Emphatic } & \multicolumn{2}{c|}{ Understating } \\
\hline \multirow{3}{*}{ Unlikelihood } & Positive P: high & 1 & even $(\mathrm{PPI})$ & 3 ? ? (NPI) \\
\cline { 2 - 5 } & Positive P: low & 2 & even (NPI) & 4 at least (PPI) \\
\hline
\end{tabular}

Rullmann (2006) assumes that there may be no items that would fit into the 'top, understating' zone in his four-way typology of even-items. This study, however, shows that the Japanese contrastive $w a$ does fit into that zone: 
Osamu Sawada

(22.) Mirror image of sae and scalar contrastive wa

\begin{tabular}{|l|l|ll|l|}
\cline { 3 - 4 } \multicolumn{2}{c|}{} & \multicolumn{2}{|c|}{ Emphatic } & Understating \\
\hline \multirow{2}{*}{ Unlikelihood } & Positive P: high & sae & (PPI) & scalar contrastive $w a(\mathrm{NPI})$ \\
\cline { 3 - 5 } & Positive P: low & sae & (NPI) & scalar contrastive $w a(\mathrm{PPI})$ \\
\hline
\end{tabular}

The Japanese scalar contrastive wa supports Rullmann's (2006) typology of even items. Giannakidou (2007) proposes a different typology of even items, which is compatible with Rullmann's typology. Her typology has two parameters: scalar value (high/low) on the likelihood scale and the presence or absence of the negative operator in the existential presupposition/conventional implicature. One of the advantages of this typology is that it can capture the fact that sae (NPI) and contrastive wa (PPI) have the same kind of existential conventional implicature.

\section{Polarity Contrastive $\mathrm{Wa}$}

Let us now turn our attention to the polarity type of contrastive wa:

(23.) Taro-wa ki-ta.

Taro-cont come-past

'[Taro] cont came.'

$\rightarrow$ There is someone other than Taro who didn't come.

(24.) Watasi wa moku-yoobi wa ai-teiru.

I Top Thursday cont free-TEIRU (stative)

'I am free on [Thursday] cont.'

$\rightarrow$ There are some days other than Thursday that I am not free.

The implicatures in (23) and (24) do not posit a scale. Contrary to Hara's (2006, to appear) claim, it seems that contrastive $w a$ does not always induce a $\mathrm{Q}$ implicature. If contrastive $w a$ is attached to non-scalar nouns or predicates, it is difficult, though not impossible, to posit an (un)likelihood scale. Oshima (to appear) argues that the semantic contribution of a contrastive morpheme is antonymous to that of the additive particle 'also.'

\section{The Difference between the Polarity Type and the Scalar Type}

Given the above analysis, how can we account for the difference between the polarity and scalar types of contrastive $w a$ ? I argue that the difference can be explained by the optionality of the scalar presupposition. The conventional implicature of polarity contrastive $w a$ in (23) is shown in (25a):
a. $\exists \mathrm{x}[\mathrm{C}(\mathrm{x}) \wedge \mathrm{x} \neq$ Taro $\wedge \neg$ came $(\mathrm{x})]$
b. $\forall \mathrm{x}[\mathrm{C}(\mathrm{x}) \wedge \mathrm{x} \neq$ Taro $\rightarrow$ unlikelihood ( $\mathrm{x}$ came) $>$ unlikelihood (Taro came)] (optional) 


\section{The Japanese Contrastive Wa}

If there is not enough information to posit a scale, one can ignore the scalar presupposition and construe contrastive $w a$ as polarity contrastive $w a{ }^{4}$ The following figure shows the landscape of wa:

\section{(26.) The landscape of $W A$}

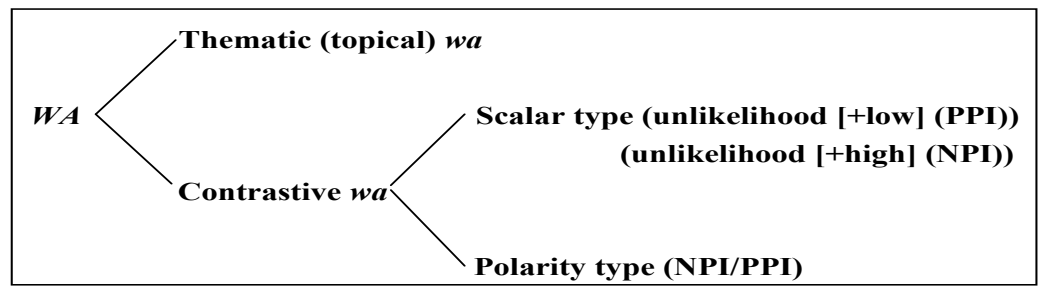

\section{Ambiguity Between the Scalar and the Polarity Types}

The instance of contrastive $w a$ in the following sentence is ambiguous; it could be read as either scalar contrastive $w a$ or polarity contrastive $w a$ :

$$
\begin{aligned}
& \text { Watasi wa ju-kiro no hako wa mot-eru. } \\
& \text { I Top 10-kilo Gen box cont lift-can } \\
& \text { 'I can lift the }[10 \text { kilo box }]_{\text {cont. }}
\end{aligned}
$$

(28.) $\rightarrow$ (scalar): I cannot lift boxes that are heavier than 10 kilos.

$\rightarrow$ (polar): There are some boxes other than the 10 kilo box that I cannot lift (e.g., there are dangerous chemicals inside the boxes).

\section{9. $\quad M o$ as the Precise Mirror Image of Contrastive $\mathrm{Wa}$}

The particle $m o$ is semantically ambiguous between a scalar additive meaning 'even' and a simple inclusive meaning 'also', as in (29). This ambiguity can also be accounted for in a unified way, based on the concept of the optionality of the scalar presupposition, as in (30b).

$$
\text { Ziro mo siken ni uka-ta. }
$$

Ziro also/even exam to pass-past

'Even Ziro passed the exam. /Ziro also passed the exam.'

(30.) Conventional implicature of $m o$

a. $\exists x\left[C(x) \wedge x \neq\right.$ Ziro $^{\wedge}$ passed $(x$, the exam $\left.)\right]$

b. $\forall \mathrm{x}[\mathrm{C}(\mathrm{x}) \wedge \mathrm{x} \neq$ Ziro $\rightarrow$ unlikelihood (Ziro passed the exam) $>$ unlikelihood (x passed the exam)] $\leftarrow$ optional

This suggests that the semantics of $m o$ and contrastive $w a$ are precise mirror opposites.

\footnotetext{
${ }^{4}$ Another approach is to consider that contrastive $w a$ is lexically ambiguous between scalar contrastive $w a$ and polarity contrastive $w a$. Notice, however, that this ambiguity is not like the ambiguity between bank meaning 'a financial institute' and bank meaning 'the side of a river.'
} 


\section{The Quantificational Variability of Contrastive $W a$}

In some contexts, the quantificational force of the existential presupposition in contrastive $w a$ can be (pragmatically) strengthened to become universal ( $\forall$ ), but in other contexts, it can be epistemically weakened to become an existential $(\exists$ ) force with a possibility operator $(\diamond)$. Let us consider an example of polarity contrastive wa:

(31.) A: Did Taro, Hanako and Ziro come to the party?

B: Taro wa ki-ta.
Taro Cont come-past
'[Taro $]_{\text {cont }}$ came.'

There are at least three possible implicatures here, according to the context:

(32.) Context A: Speaker B knows that Taro came to the party and Hanako didn't come, but does not know whether or not Ziro came.

In this context (31B) implies that 'there is someone other than Taro who didn't come.' This implicature has existential force.

(33.) Context B: Speaker B knows that Taro came to the party, and that Hanako and Ziro didn't.

In this context, (31B) implies that 'no one other than Taro came to the party.' This implicature has universal force. That is to say, the existential presupposition of contrastive $w a$ is pragmatically strengthened. Context B is a situation in which only is used. ${ }^{5}$

(34.) Context C: Speaker B knows that Taro came to the party but is not sure whether Hanako or Ziro came.

5 There is still a semantic difference between dake 'only' and contrastive wa in context $\mathrm{B}$, as regards contrastiveness:
( i ) Taro wa ki-ta.
Sikasi Hanako to Ziro wa ko-naka-ta.
Taro Cont come-past but Hanako and Ziro Cont come-not-past '[Taro $]_{\text {Cont }}$ came but [Hanako and Ziro $]_{\text {Cont }}$ didn't.'
(ii ) \#Taro dake ki-ta. Sikasi Hanako to Ziro wa ko-naka-ta. Taro only come-past but Hanao and Ziro Cont come-not-past '\#Only Taro came but [Hanako and Ziro $]_{\text {cont }}$ didn't.'

Sentence ( $\mathrm{i}$ ) with contrastive wa can explicitly contrast Taro with partygoers Hanako and Ziro, but sentence ( ii ) cannot make this contrast explicitly. 


\section{The Japanese Contrastive $\mathrm{Wa}$}

In this context, (31B) implies that 'it is possible that there is someone other than Taro who didn't come.' The possibility operator is attached to the existential presupposition in this case.

The implicature generated by scalar contrastive $w a$ also has quantificational variability. Thus, the conventional scalar implicature that 'a stronger proposition is not true' may become the weaker implicature that 'a stronger proposition may not be true.'

\section{Conclusion}

This paper has argued that there are two types of contrastive $w a$, a scalar type and a polarity type. The conventional implicatures of scalar contrastive $w a$ are a mirror image of those generated by sae 'even', whereas the conventional implicature of polarity contrastive $w a$ appears because of the optionality of the scalar presupposition in scalar contrastive wa. Positing the existence of two types of contrastive $w a$ reconciles seemingly incompatible approaches, the reversed polarity approach and the scalar alternative approach. I hope this paper sheds new light on the study of contrastiveness. It may be possible to consider that the same analyses can apply to the Korean contrastive marker -nun.

In a future study, I would like to consider the semantic/pragmatic difference between scalar contrastive $w a$ and adverbs such as sukunaku-tomo '(lit) little-even if' and saitei-demo '(lit) the least-even if':

$$
\begin{aligned}
& \{\text { Sukunaku-tomo/ saitei-(demo)\} juu-nin ki- ta. } \\
& \text { Little CONC/ lowest CONC ten-CL (person) come-past } \\
& \text { 'At least ten people came.' (No negative implicature.) } \\
& \text { Juu-nin wa ki-ta. } \\
& \text { Three-CL (person) cont come-past } \\
& \text { '[Ten people }]_{\text {Cont }} \text { came.' } \\
& \text { (Implicature: I am not sure whether more than ten people came.) }
\end{aligned}
$$

It seems that sukunaku-tomo and saitei(-demo), block a Q implicature but scalar contrastive wa does not.

\section{References}

Borkin, Ann. 1971. Polarity Items in Questions. Papers from the Seventh Regional Meeting of the Chicago Linguistic Society 7, 53-62.

Giannakidou, Anastasia. 2007. The Landscape of EVEN. Natural Language and Linguistic Theory 25:39-81.

Hara, Yurie. 2006. Implicature Unsuspendable: Japanese Contrastive wa. Proceedings of the 2004 Texas Linguistic Society Conference: Issues at the Semantics-Pragmatics Interface, 35-45. 
Hara, Yurie. To appear. Scope Inversion in Japanese: Contrastive Topic Requires Scalar Implicatures. Japanese/Korean Linguistics 13. Stanford, CA: CSLI.

Israel, Michael. 1996. Polarity Sensitivity as Lexical Semantics. Linguistics and Philosophy 19:619-666.

Karttunen, Lauri, and Stanley Peters. 1979. Conventional Implicature. In C. K. Oh and D. A. Dinneen, eds., Syntax and Semantics. Vol. 11. Presupposition, 1-56. New York: Academic Press.

Kay, Paul. 1990. Even. Linguistics and Philosophy 13:59-111.

Kuno, Susumu. 1973a. Nihon Bunpoo Kenkyuu (The study of Japanese Grammar). Toyko: Taisyuukan.

Kuno, Susumu. 1973b. The Structure of Japanese Language. Cambridge, MA: MIT Press.

Ladusaw, William. A. 1980. Polarity Sensitivity as Inherent Scope Relations. New York \& London: Garland Publishing.

Lee, Chungmin. 2000. Contrastive Predicates and Conventional Scales. In A. Okrent and J. Boyle, eds., Papers from the $36^{\text {th }}$ Annual Meeting of the Chicago Linguistic Society, 243-257.

Lee, Chungmin. 2006. Contrastive Topic/Focus and Polarity in Discourse. In K. von Heusinger and K. Turner, eds., Where Semantics Meets Pragmatics, 381420. New York: Elsevier.

Nakanishi, Kimiko. 2001. Prosody and Information Structure in Japanese: A Case Study of Topic Marker wa. In N. Akatsuka and S. Strauss, eds., Japanese/Korean linguistics 10, 434-447. Stanford, CA: CSLI.

Noda, Hisashi. 1996. Wa to Ga (Wa and ga). Tokyo: Kuroshio.

Oshima, David. To appear. Morphological vs. Phonological Contrastive Topic Marking. Papers from the $41^{\text {st }}$ Meeting of the Chicago Linguistic Society.

Rooth, Mats. 1985. Association with Focus. Ph.D. diss., University of Mas sachusetts at Amherst.

Rullmann, Hotze. 1997. Even, Polarity, and Scope. In M. Gibson, G. Wiebe, and G. Libben, eds., Papers in Experimental and Theoretical Linguistics Vol.4, 40-64. Edmonton: University of Alberta.

Rullmann, Hotze. 2006. Does Even Even Have Scope? Handout of Linguistics Colloquium at University of Chicago.

Sawada, Osamu. 2007. Pragmatic Aspects of Implicit Comparison. Paper Presented at the 81st Annual Meeting of the Linguistic Society of America. Ana heim, CA. January 6.

Teramura, Hideo. 1991. Nihongo no Sintakusu to Imi III (Syntax and Semantics of Japanese III). Tokyo: Kuroshio.

Yoshimura, Keiko. To appear. Scope Theory vs. Polarity Theory: Analysis of Japanese Focus Particle -Sae. Papers from the $40^{\text {th }}$ Annual Meeting of the Chicago Linguistic Society. 
The Japanese Contrastive $W a$

Osamu Sawada

University of Chicago

Department of Linguistics

1010 East $59^{\text {th }}$ street

Chicago IL 60637, USA

sawadao@uchicago.edu 